\title{
Altered Growth and Protein Turnover in Rats Fed Sodium-Deficient Diets
}

\author{
STEVEN J. WASSNER \\ with the technical assistance of Deborah Fenstermacher \\ Penn State University College of Medicine, University Hospital, The Milton S. Hershey Medical Center. \\ Hershey, Pennsylvania 17033
}

\begin{abstract}
The effects of feeding a sodium-deficient (NaD) diet were examined in young, growing rats. All animals were fed the same diet and drank distilled water. In the control group the water contained $37 \mathrm{mM}$ sodium chloride. After 2-3 wk body composition measurements were performed and epitrochlearis muscle protein synthesis and degradation rates determined. The experimental group gained only $45 \%$ of the wt and $70 \%$ of the length seen in the control group. The difference in wt gain could not be accounted for by differences in extracellular volume which averaged only $4 \%$ of body wt. Although total food intake was equivalent in both groups, urinary ammonia plus urea nitrogen excretion was higher in the experimental animals. Protein synthesis, measured as the incorporation of ${ }^{14} \mathrm{C}$-phenylalanine into muscle protein was significantly lower in $\mathrm{NaD}$ rats $(56.58$ versus 68.79$)$ and $(65.26$ versus $83.88 \mathrm{nmol}$ phenylalanine/h/g wet wt (both $p<0.01$ ) when incubated with or without the addition of insulin $(1 \mathrm{mU} /$ $\mathrm{mL}$ ). Net protein degradation rates were unchanged. Gastrocnemius muscle RNA concentrations were also lower in $\mathrm{NaD}$ rats $(1.09$ versus $1.52 \mathrm{mg} / \mathrm{g}$ wet $\mathrm{wt}, p<0.001)$. There were no changes noted in the concentration of protein within either gastrocnemius or epitrochlearis muscles. These results suggest that in rats, the growth failure seen in sodium deficiency: 1 ) affects both length and wt gain; 2) is not associated with decreased nutrient intake; 3 ) is due to decreased rates of muscle protein synthesis without affecting net protein degradation rates; and 4 ) is associated with diminished muscle tissue RNA concentrations. ( $P e^{-}$ diatr Res 26: 608-613, 1989)
\end{abstract}

\section{Abbreviations}

$\mathrm{NaD}$, sodium deficient

TCA, trichloroacetic acid

PUN, plasma urea nitrogen

ECF, extracellular fluid

Sodium is the most abundant cation within the extracellular space and sodium depletion is commonly associated with wt loss, hypovolemia, and dehydration (1). In pediatrics, chronic sodium deficiency is most often encountered either due to congenital urinary tract abnormalities (2), gastrointestinal salt loss (3), or iatrogenicly, with the chronic administration of potent diuretics such as furosemide (I). Although first noted over $50 \mathrm{y}$ ago, it is still not commonly appreciated that sodium depletion affects not only extracellular volume, but growth and nitrogen retention as well (4-6). Kahlenberg et al. (4) first reported that feeding young

Received April 21, 1989; accepted July 13, 1989 rats $\mathrm{NaD}$ diets was associated with decreased wt gain and diminished nitrogen retention. More recently, poor wt gain and accretion of lean body mass has been noted in humans receiving hyperalimentation with $\mathrm{NaD}$ infusates (6) as well as in rats made $\mathrm{NaD}$ either through the use of $\mathrm{NaD}$ diets or by the administration of furosemide $(7,8)$. Fine et al. (7) have documented that, in rats, even short periods of sodium depletion have major detrimental effects on wt gain and the accretion of protein mass (7).

With the exception of the papers noted above, few investigators have examined the relationship between sodium and protein turnover. Inasmuch as muscle tissue is the largest single protein mass within the body, it is likely that the effects of sodium deficiency are present within muscle tissue as well.

In this report we report on the effects of feeding young rats a $\mathrm{NaD}$ but otherwise nutritionally complete diet. We studied the effects of isolated sodium deficiency on wt gain and body composition, food intake, and muscle protein turnover rates. These studies document that, in addition to the well-known extracellular volume changes, sodium deficiency is also associated with altered body composition mediated by changes in protein turnover rates within muscle tissue.

\section{MATERIALS AND METHODS}

Weanling Sprague-Dawley rats were obtained from a commercial supplier (Charles River Laboratories, Wilmington, MA). After release from quarantine the rats were weighed, housed in individual cages, and randomly allocated to two groups. Both groups received the same sodium deficient test diet (no. 170950 Teklad, Madison, WI) prepared in powder form. The diet provides approximately $4.2 \mathrm{kcal}$ and between 2 and $9 \mu \mathrm{Eg} \mathrm{Na} / g$ diet (A. Langbehn, personal communication, Teklad). The experimental group received distilled water, whereas the control group received distilled water containing $37 \mathrm{mM}$ sodium chloride. The food was placed in individual stainless steel containers and then weighed using an electronic balance. Excess quantities of food were always present in the containers. New aliquots of food were provided every other day and the food remaining in the container was also weighed. Examination of the cages revealed that wastage was negligible. The rats were weighed twice a week at the same time as the food was changed and the weight noted to the nearest $0.1 \mathrm{~g}$. Rat length was determined with the rat lightly anesthetized with methoxyfluorane. The rats were measured from tail to snout and length noted to the nearest $0.1 \mathrm{~cm}$. For some studies the rats were transferred to metabolic cages and 24-h urine collections were obtained several days later. At the end of the 24 -h collection period, the collection funnel was washed with distilled water to ensure complete collections.

On the day protein turnover studies were performed, rat urine was obtained by stimulated voiding. The rats were anesthetized with methoxyfluorane and both epitrochlearis muscles rapidly removed. If necessary, urine was obtained by bladder aspiration and blood was obtained from the descending aorta. When re- 
quired, samples of gastrocnemius muscle were removed at this time, frozen between Wollenberger clamps previously cooled in liquid nitrogen, and stored at $-70^{\circ} \mathrm{C}$. Muscle incubation was performed according to established methods (9). Briefly, each muscle was gently blotted, weighed and transferred to preincubation flasks containing $3 \mathrm{~mL}$ of Krebs-Henseleit Ringer buffer (pH 7.4) previously equilibrated with a $95 \% / 5 \% \mathrm{O}_{2} / \mathrm{CO}_{2}$ gas mixture. The buffer contained $146 \mathrm{mM} \mathrm{Na}, 10 \mathrm{mM}$ glucose, and $0.5 \mathrm{mM}$ phenylalanine. Alternate muscles were incubated in mixtures containing beef insulin added at a concentration of 1.0 $\mathrm{mU} / \mathrm{mL}$ medium to both the preincubation and incubation flasks. After a 30-min preincubation in a shaking water bath at $37^{\circ} \mathrm{C}$, each muscle was removed from its stoppered flask, gently blotted, and transferred to another pregassed flask containing the same constituents plus ${ }^{14} \mathrm{C}$-phenylalanine (at a concentration of $0.07 \mu \mathrm{Ci} / \mathrm{ml}$ medium ) and incubated for an additional $2 \mathrm{~h}$.

At the end of the incubation period the tissue was removed from the flask, blotted, cut with a fine scissors, and placed in a glass homogenizer containing $1 \mathrm{~mL}$ of $10 \% \mathrm{TCA}$. An aliquot of the incubation medium was taken and deproteinated with an equal volume of $10 \%$ TCA. The supernatant was then stored at $-70^{\circ} \mathrm{C}$. The muscle was homogenized, the suspension cooled on ice for $10 \mathrm{~min}$, centrifuged, and the supernatant removed and stored at $-70^{\circ} \mathrm{C}$. The precipitate was then resuspended in an additional $1 \mathrm{~mL}$ of $10 \% \mathrm{TCA}$, centrifuged, and the supernatant discarded. The protein pellet was washed twice using a mixture of ethanol:ether $(1: 1)$ and the resulting protein pellet redissolved overnight at $40^{\circ} \mathrm{C}$ in $1 \mathrm{~mL}$ of $1 \mathrm{~N} \mathrm{NaOH}$.

Radioactivity was determined in both the dissolved protein pellet and protein-free medium by scintillation counting. Counts were converted to dpm through the use of external standardization. The concentration of phenylalanine within the medium was determined using the method of Andrews et al. (10). The concentration of tyrosine within the incubation medium was determined using the method of Waalkes and Udenfriend (11). The use of phenylalanine and tyrosine are dictated by the fact that these amino acids are neither produced nor degraded within muscle tissue (12) so that incorporation of radioactivity accurately reflect ongoing rates of protein synthesis within this tissue.

Samples of frozen gastrocnemius muscle were ground to a fine powder using a mortar and pestle previously cooled in liquid nitrogen and stored frozen until assayed for protein and RNA using the methods of Lowry et al. (13) and Fleck and Munro (14), respectively.

Serum and urine sodium and potassium were determined using a flame photometer (Instrumentation Laboratories, Lexington, MA) and chloride using a Gemini centrifugal analyzer (Electro-Nucleonics, Fairfield, NJ). Total bicarbonate levels were calculated using a Corning blood gas analyzer (Corning Glass Works, Corning, NY). PUN, urinary urea, ammonia nitrogen, and creatinine concentrations were determined using commercial kits nos. 640-A and 555-A, respectively (Sigma Chemical Co., St. Louis, MO).

For determination of ECF volumes, rats were anesthetized with intraperitoneal pentobarbital $(65 \mathrm{mg} / 100 \mathrm{~g}$ body $\mathrm{wt})$ and bilateral nephrectomies were performed through flank incisions.
Immediately thereafter the animals received intraperitoneal injections of known amounts of ${ }^{14} \mathrm{C}$-inulin. The animals were killed $2 \frac{1}{2} \mathrm{~h}$ later by exsanguination through the abdominal aorta, the serum separated and, after precipitation, an aliquot counted in the liquid scintillation counter along with an aliquot from the initial radioactive inulin injected. The volume of distribution of labelled inulin is taken as an approximation of the extracellular fluid volume (15). Total body water was calculated from the difference between the wet and dry wt of a muscle sample dried at $50^{\circ} \mathrm{C}$ for $48 \mathrm{~h}$. The extracellular space of incubated epitrochlearis muscle was determined by adding ${ }^{14} \mathrm{C}$-inulin to the incubation medium $10 \mathrm{~min}$ before the end of the incubation period. Ten min later the tissue was removed, rinsed, blotted, and dissolved in $1 \mathrm{~mL} 1 \mathrm{~N} \mathrm{NaOH}$.

Scintillation counting was performed using Formula 963 scintillation fluid (NEN Research Products, Boston, MA) with correction for quenching using external standardization. Rates of epitrochlearis muscle protein synthesis were calculated using the following formula (16):

synthesis $=\mathrm{dpm}{ }^{14} \mathrm{C}$-phe $\mathrm{pellat} /\left(\mathrm{S} . \mathrm{A} \cdot{ }^{14} \mathrm{C}-\right.$ phe $\left._{\text {incubation }}\right) / \mathrm{g}$ wet wt $/ 2 \mathrm{~h}$

Where synthesis (nmol/g wet wt/h) equals the $\mathrm{dpm}$ incorporated into the protein pellet divided by the sp act of phenylalanine in the incubation medium. At the concentration of phenylalanine used ( $>5 \times$ normal rat plasma levels), medium and intracellular phenylalanine-sp act rapidly equilibrate (7) and the sp act of medium can therefore be used for the calculation of epitrochlearis muscle protein synthesis rates (16).

Net protein degradation within the epitrochlearis muscle can be calculated from the net release of tyrosine into the incubation medium as follows (16):

degradation $=$ medium tyrosine content $(\mathrm{pmol} / \mathrm{g}$ wet wt $/ 2 \mathrm{~h})$

This calculation reflects the difference between the ongoing rates of protein degradation and synthesis within muscle (17).

Except as noted, all data are reported as the mean $( \pm 1 \mathrm{SE})$ of eight to 25 values. Statistical analysis was performed using Student's $t$ test, analysis of variance, and the Neumann-Keuls test. A $p<0.05$ was considered significant. There were no significant interexperiment differences noted for either control or $\mathrm{NaD}$ rats so grand means are reported.

\section{RESULTS}

After 2 wk of eating the identical diets, the experimental $\mathrm{NaD}$ group demonstrated mild hyponatremic dehydration, Table 1 lists the mean PUN, creatinine, serum, and urine electrolyte values noted for both groups. The PUN values in the experimental group were twice as high as in the control group. Plasma creatinine levels were also higher in the $\mathrm{NaD}$ rats but the difference did not reach statistical significance. Despite of the changes noted in PUN and creatinine levels, 24-h creatinine clearances were not significantly different between the two groups of animals, suggesting that the salt deficient rats were not grossly dehydrated at the time of study (Table 1). Urinary urea clearances

Table 1. Serum and urine values in sodium-deficient and sodium-supplemented rats

\begin{tabular}{|c|c|c|c|c|c|c|c|c|c|c|c|}
\hline & \multirow{2}{*}{$\begin{array}{l}\text { Serum } \\
\text { urea } \\
\text { nitrogen } \\
\mathrm{mmol} / \mathrm{L}\end{array}$} & \multirow[b]{2}{*}{$\begin{array}{c}\text { Creatinine } \\
\mu \mathrm{mol} / \mathrm{L}\end{array}$} & \multirow[b]{2}{*}{$\underset{\mathrm{mEq} / \mathrm{L}}{\mathrm{Na}}$} & \multirow[b]{2}{*}{$\underset{\mathrm{mEq} / \mathrm{L}}{\mathrm{K}}$} & \multirow[b]{2}{*}{$\underset{\mathrm{mEq} / \mathrm{L}}{\mathrm{Cl}}$} & \multirow[b]{2}{*}{$\begin{array}{c}\mathrm{HCO} 3 \\
\mathrm{mmol} / \mathrm{L}\end{array}$} & \multicolumn{3}{|c|}{ Urine } & \multirow[b]{2}{*}{$\begin{array}{c}\text { Urea N } \\
\mathrm{mmol} / 24 \mathrm{~h}\end{array}$} & \multirow[b]{2}{*}{$\begin{array}{c}\mathrm{C}_{\mathrm{cr}} \\
\mathrm{mL} / 24 \mathrm{~h}\end{array}$} \\
\hline & & & & & & & $\underset{\mathrm{mEq} / \mathrm{L}}{\mathrm{Na}}$ & $\underset{\mathrm{mEq} / \mathrm{L}}{\mathrm{K}}$ & $\underset{\mathrm{mEq} / \mathrm{L}}{\mathrm{Cl}}$ & & \\
\hline \multirow{2}{*}{ Sodium deficient } & $13.5^{*}$ & 46 & 134 & 6.2 & 98 & 23.9 & $00^{\dagger}$ & 326 & 126 & 7.3 & 647 \\
\hline & 0.7 & 2 & 1 & 0.3 & 1 & 0.9 & & 27 & 23 & 1.4 & 60 \\
\hline \multirow[t]{2}{*}{ Sodium supplement } & 6.5 & 39 & 139 & 4.1 & 99 & 25.1 & 23 & 139 & 87 & 5.2 & 769 \\
\hline & 0.2 & 2 & 1 & 0.3 & 1 & 0.3 & 3 & 21 & 15 & 1.0 & 55 \\
\hline$p$ & $<0.001$ & 0.066 & $<0.002$ & $<0.001$ & 0.59 & 0.17 & $<0.001$ & $<0.001$ & 0.16 & $<0.005$ & 0.14 \\
\hline
\end{tabular}

* Mean \pm I SE.

† Less than $5 \mathrm{mEq} / \mathrm{L}$. 